\title{
PSYCHO-BEHAVIOURAL HEALTH AND PERSONALITY IN SOUTHERN NIGERIA: PERSPECTIVES ON EMOTION
}

\author{
Veronica O. Ezebuiro, $\mathbf{P h D}^{1 *}$, Jacinta A. Opara, $\mathbf{P h D}^{2}$
}

*1 Department of Physical and Health Education Alvan Ikoku College of Education Owerri, Imo State-Nigeria

${ }^{2}$ Department of Biological and Environmental Sciences Kampala International University Kampala-Uganda

\section{*Corresponding Author: -}

\begin{abstract}
: -
The study identified the mental and emotional health needs of adolescents in the Niger Delta region of Nigeria with special reference to Rivers State. Four specific objectives with corresponding research questions and one null hypothesis guided the study. The study utilized cross-sectional research design. The study covered a population of 1,559,615 adolescents in Rivers State. A sample of 1,632 adolescents filled the questionnaire but data from 1375 copies of completed questionnaire representing 84 per cent return rate were used for analysis. Multistage sampling procedure was adopted to draw the sample from the population. The instruments for data collection were a questionnaire and focus group discussion guide. Means and standard deviation were utilized to answer the research questions, while t-test and ANOVA were utilized in testing the hypotheses at .05 level of significance. Qualitative data generated from the focus group discussion were used to substantiate the quantitative data. The finding of the study revealed that adolescents in Rivers State have mental and emotional health needs always; both male and female, age groups 10-15years, 16-18years and 19-24years; and urban and rural adolescents have the needs always. Based on the findings, it was recommended among others that programmes should be put in place in order to meet and satisfy adolescents mental and emotional health needs.
\end{abstract}

Keywords: Mental Health, Emotional health, Needs, Adolescents, Emotional health needs.

\section{(c) $(\$)$}




\section{INTRODUCTION}

Generally, individuals are faced with mental and emotional health needs. Individual's actions are indications of an attempt to satisfy needs. When these needs are satisfied, their behaviours see them as happy successful persons who enjoy life. Unsuccessful attempts particularly by the adolescents to satisfy needs engender actions which will lead to becoming misfits, trouble makers, alcoholics and sociopaths who are unable to adapt and function responsibly in social settings.

WHO (1998) defined adolescents as individuals/youths between the ages of 10 and 25 years. Onuzulike (2007) referred to an adolescent as a young boy or girl in the process of developing from child into adult. The author added that adolescence is roughly between the age of 13 and 18 years. For the present study, adolescent is a girl or boy between the age of 10 and 24 years transiting from childhood to adulthood with the resultant physical, mental, emotional and behavioural health changes of which he or she has no or little control over. Rather than adhere to a strict definition of the age range, this study uses the terms young people, youths and adolescents interchangeably to refer to the $10-24$ age group. This broader use of the terms underscores the need for programmes to focus less on age and more on recognizing the specific developmental mental and emotional health needs and problems of people as they transit from childhood to adulthood. Wagner (2008) submitted that they are at such a vulnerable age. They are going through major changes in their lives hormonally, they are growing, they are looking for their niche a lot which is very stressful. Often, when adolescents feel that they cannot meet the current social standards of beauty or perfection, they turn their anger and frustration onto their own bodies, developing problems which invariably will affect their mental and emotional health.

WHO (2005) defined mental health as a state of well-being in which the individual realizes his or her own abilities, can cope with the normal stresses of life, can work productively and fruitfully, and is able to make a contribution to his or her community. In 1999, the Surgeon General, then David Satcher, conceived of mental health as a state of successful performance of mental function, resulting in productive activities, fulfilling relationships with people, and ability to adapt to change and to cope with adversity.

Emotional health is the state of one's mind towards one's self and others. Reed-Flora and Lang (1982) asserted that emotions are not the result of people doing things to us or for us. They are a result of how we learned to react to what happens to us. They added that we, not other, are responsible for our emotion. Okafor and Okafor (1998) defined emotion as a strong feeling of any kind: love, joy, hate, fear and grief. Emotional health was defined by O'Donnell (2002) as one's mental state of being. It encompasses the stress in a person's life, how one reacts to those stresses, and the ability to relax and devote time to leisure. Emotional health can be defined as a state where you are in control of your thoughts, feelings and behaviours. You feel good about yourself and your relationships and can keep problems in perspectives (Your Health, 2011). Furthermore, emotionally healthy people can still have emotional problems and needs, but they have learned of ways to cope with stress and problems and know when to seek help from their doctor or counselor. Park (2007) stated that emotional health relates to feeling. Emotional health according to Deal Fact Sheet (2011) refers to part of our overall health which is concerned with the way we think and feel. It refers to our sense of well-being, and our ability to cope with life events. More so, emotional health is about our ability to acknowledge and respect our own emotions as well as those of others. In this study, emotional health shall be defined as the way one think, feel and react to situations within and around us. The two major determinants of behaviour and emotion are self-concept and our emotional needs.

A need is a necessity and something that is basic in life. A need according to Huffstetler (2013) is something you have to have. Needs arise from the interaction of the individual with his total psychological environment. Such needs are individualized and are as unique as the numerous situations which an individual experiences (Udoh \& Ajala, 2012).

Essential to mental health, as well as to life itself according to Reed-Flora and Lang (1982) are our emotional needs. These needs include: the need to live which implies that we must want to be alive, even if it is only to avoid death. Hope is the essential ingredient to remaining alive. The need to feel important - we must feel that we are worth something to ourselves, that we are valuable in and of our own right, and that we can contribute significantly to ourselves and others. The need for variety - we need to be stimulated and to react to the stimulation, and we need to experience change. Furthermore, the need to be loved - we must feel that we are worth something to others- that we are valuable enough to deserve the attention that it takes to have our needs met. The need to achieve - we need to be productive and creative, to feel that we have an impact on our environment; and the need for value orientations and moral reasoning - we need to have a sense of right and wrong, a way to make decisions, a philosophy of life that structures our experiences and gives them a meaning or purpose (Reed-Flora \& Lang, 1982). Okafor and Okafor (1998) added that the emotional needs include sense of security, love and affection, self acceptance, freedom, variety of experiences, guidance, faith in power, time for contemplation, need to be accepted by others and ambition to succeed in life. When an adolescent is able to deal with these needs constructively, he or she is likely to be said to be emotionally healthy.

The human needs abound all over the world. The old ones, the young and children have mental and emotional health needs such as need for love, need for security, self-esteem, selfactualization, independence, need to be successful, need for recognition (Udoh \& Ajala, 2012). Such needs are individualized and are as unique as the numerous situations which an individual experience including adolescents. It is therefore, pertinent to identify the mental and emotional health needs of adolescents in River State.

\section{Purpose of the Study}

The purpose of the study is to identify the mental and emotional health needs of adolescents in Rivers State. Specifically, this study seeks to:

1. identify mental and emotional health needs of adolescents in Rivers State;

2. determine the mental and emotional health needs of adolescents in Rivers State according to gender; 
3. determine the mental and emotional health needs of adolescents in Rivers State according to age;

4. determine the mental and emotional health needs of adolescents in Rivers State according to location.

\section{Research Questions}

The following research questions are formulated to guide the present study.

1. What are the mental and emotional health needs of adolescents in Rivers State?

2. What are the mental and emotional health needs of adolescents in Rivers State according to gender?

3. What are the mental and emotional health needs of adolescents in Rivers State according to age?

4. What are the mental and emotional health needs of Adolescents in Rivers State according to location?

\section{Hypotheses}

The following hypotheses were postulated for the present study to be tested at 0.05 level of significance:

1. There is no significant gender difference in the prevalent mental and emotional health needs of adolescents in Rivers State.

2. There is no significant age difference in the mental and emotional health needs of adolescents in Rivers State.

3. There is no significant difference in the mental and emotional health needs of adolescents in Rivers State according to location.

\section{Methods}

The cross-sectional survey research design was used to achieve the purpose of the study. Cross-sectional survey research design according to Frankel and Wallen (2003) and Anaekwe (2007) is useful for studying a variety of problems involving data collection for answering research questions or testing hypotheses concerning the present situation or status of the subject under study. They further asserted that this design permits the description of condition or subjects as they exist in their natural settings. Bhui et al. (2005) utilized this design to investigate cultural identity as a risk factor for mental health problems among adolescents in east London. The cross-sectional survey research design was therefore considered appropriate for use in this present study.

The population for the study comprised all the adolescents aged 10-24 years in Rivers State and is estimated to be 1,559,615 which is 30 per cent of Rivers State population. This percentage and figure is a record from the National Population Commission (NPC), Rivers State. According to NPC (2006), Rivers State had a population of 5,198,716.

The sample size for this study was 1632 adolescents. The technique that was used to arrive at the sample size was the multi-stage sampling procedure. The first stage involved purposive sampling of 2 LGAs from each of the 3 senatorial zones of Rivers State to arrive at 6 LGAs. The second stage involved stratifying the six LGAs into three urban and three rural LGAs. The third stage involved disproportionate selection of 4 communities from each of the 6 LGAs to have 24 communities. The fourth stage involved simple random selection of 68 adolescents from each of the 4 communities from each of the six LGAs ( 816 adolescents from the 3 urban LGAs and 816 from the 3 rural LGAs or 272 adolescents from each LGA.). This gave a sample size of 1632 adolescents for the study.

The researcher designed adolescents' mental and emotional health needs questionnaire (AMEHN-Q) and focus group discussion (FGDG) were the instruments for data collection. The questionnaire was divided into three sections section A and B. Section A contained three demographic variables of age, gender and location. Section B contained 10 items on mental and emotional health needs of adolescents. All the items on sections B were assigned four-point scale response options. The options range from Always (AL) - 4, Sometime (ST) - 3, Occasionally (OC) - 2 and Never (N) - 1 . The respondents were requested to tick $(V)$ against the option that applied to them.

The FGDG was based on questions that were prepared in line with the research objective to elicit information on the mental and emotional health needs of adolescents. A tape recorder and six new cassettes were used to record the proceeding of the discussion. Also, research assistants were used to document the proceedings of the FGD.

The face and content validity of the instrument was established through multidisciplinary validation in which the AMEHN-Q was given to five experts: two from the Department of Health and Physical Education, two from Psychology and one expert in Measurement and Evaluation. The purpose of the study, research questions and hypotheses of the study accompanied the instrument. The experts critically examined the specific sections and items of the instrument and established its correspondence with the objectives, research questions and hypotheses. They also determined the suitability, clarity, appropriateness of the language and the ability of the instrument to elicit the desired information that was used to achieve the purpose of the study.

The reliability of the instrument was determined using pretest. Cronbach Alpha was used to measure the internal consistency of an instrument. The instrument was pre-tested on twenty adolescents from Bayelsa State. The data was coded in the computer using statistical package for social sciences version 16 (SPSS 16). According to Udegbe (2007), if the correlation coefficient attains .67 or above, the instrument will be considered reliable and suitable for gathering information towards achieving the purpose of the study. Following from this, the reliability index of .94 was obtained and the questionnaire was therefore considered reliable for the achievement of the purpose of the study.

The researcher used two CBOs who are located in the communities for data collection. The researcher used three members from each of the two CBOs as research assistants. The choice for the use of the $\mathrm{CBO}$ s was because they already operate in the communities and had already created enabling environment for operation. More so, they work with the youths which facilitated access to adolescents in the communities. A meeting was held with the CBOs where they were briefed on the mode of data collection and the content of the AMEHN-Q. They were used to administer the questionnaire. The questionnaire was administered and collected on the spot but those that were not collected on the spot were collected 
on a later date to ensure high return rate. 1632 copies of the questionnaire were administered, 1375 copies were completed correctly and returned representing 84 per cent return rate.

AMEHN-Focus group discussion guide (AMEHN-FGDG) was used to source for qualitative data. The focus group discussion was organized among adolescents, two groups from each of the six states sampled making it 12 groups in all. The AMEHN-FGD was conducted by the researcher and two research assistants. The focus group consisted of twelve adolescents in each group. At the end, the qualitative data were generated from twelve different groups with two focus groups from each state. The researcher with the two research assistants conducted all the groups discussion. Each group lasted for a maximum of fifty minutes. In each of the focus group, the researcher served as the facilitator while the other two research assistants served as the documenters of the discussion proceedings.

The data collected was analyzed using SPSS 16. The data that was generated from research questions 1 to 4 was presented using limits of whole numbers mean. Means and standard deviations were used for the purpose of description. The means and standard deviations were used to answer research questions 1 to 4 . For description of data in the study, the limits of whole numbers mean scores are presented as follows:

$$
\begin{aligned}
& \text { Always }=3.50-4.00 \\
& \text { Sometime }=2.50-3.49 \\
& \text { Occasionally }=1.50-2.49 \\
& \text { Never }=0.00-1.49
\end{aligned}
$$

Therefore, for the purpose of description and answering the research questions, a mean score between 3.50 and 4.00 indicated that the adolescents have mental and emotional health needs always. A mean score between 2.50 and 3.49 indicated that they have mental and emotional health needs sometime, a mean score between 1.50 and 2.49 indicated that they have the needs occasionally and a mean score between 0.00 and 1.49 indicated that they never have mental and emotional health needs. This implied that the adolescents have mental and emotional health needs when the mean scores fall between 1.50 and 4.00. But when the mean score of the needs fell between 0.00 and 1.49, it implied that they do not have the needs. ANOVA statistic was used to test hypothesis 2 while the t-Test statistic was used to test for hypotheses 1 and 3. All the hypotheses were tested at .05 level of significance.

The qualitative data that was generated from the FGD was edited. The non verbal communications were interpreted. The interpreted non verbal communications and documented verbal communications of the various groups were compiled and grouped according to responses similar. They were analyzed thematically and were used to substantiate the quantitative data.

\section{Findings}

\section{Research question one.}

What are the mental and emotional health needs of adolescents? Data answering this research question are contained in Table 1.

Table:1. Mean Rating of Mental and Emotional Health Needs of Adolescents ( $n=1375)$.

\begin{tabular}{lllll}
\hline S/N & Mental and Emotional Health Needs & Mean & SD & Decision \\
\hline 1. & I like to be alive & 3.79 & .637 & Always \\
2. & $\quad$ I feel I am important in life & 3.75 & .632 & Always \\
3. & $\quad$ I like to experience changes in life & & & \\
& $\quad$ situations & 3.55 & .710 & Always \\
4. & $\quad$ I feel that I should be loved & 3.61 & .721 & Always \\
5. & $\quad$ I feel like doing something new & & \\
& $\quad$ eg drawing and painting & 3.25 & .894 & Sometime \\
6. & I feel I need security or protection in life & 3.26 & 1.000 & Sometime \\
7. & $\quad$ I feel I should be accepted by self and & & & \\
& $\quad$ by others & 3.53 & .804 & Always \\
8. & I need to be successful in life & 3.77 & .662 & Always \\
9. & I feel like having a variety of experiences & 3.40 & .821 & Sometime \\
10. & I need guidance in life & 3.63 & .784 & Always \\
\hline & Overall Mean & $\mathbf{3 . 5 5}$ & & Always \\
\hline
\end{tabular}

Table 1 shows the mean rating scores and standard deviations for the items: I like to be alive $(\bar{X}=3.79, \mathrm{SD}=.637)$, I need to be successful in life $(\bar{X}=3.77, \mathrm{SD}=.662)$, I feel I am important in life $(\bar{X}=3.75$, $\mathrm{SD}=.632)$, I need guidance in life $(\bar{X}=3.63, \mathrm{SD}=.784)$, I feel that I should be loved $(\bar{X}=3.61, \mathrm{SD}=.721), \mathrm{I}$ like to experience changes in life situations $(\bar{X}=3.55, \mathrm{SD}=.710)$ and I feel I should be accepted by self and by others $(X=3.53$, $\mathrm{SD}=.804)$ which fell between the means of 3.50 and 4.00. This implies that adolescents have these needs always. The table further shows the mean score and standard deviations for items I feel like doing something new eg drawing and painting ( $\bar{X}=3.25, \mathrm{SD}=.894)$, I feel I need security or protection in life $(\bar{X}=3.26, \mathrm{SD}=1.000)$ and I feel like having a variety of experiences $(\bar{X}=3.40, \mathrm{SD}=.821$ ) which fell between the means of 2.50 and 3.49 . This implies that adolescents sometime have these needs. The table also indicates an overall mean rating of 3.55. This implies that the adolescents have 
mental and emotional health needs always. The standard deviations which range from .632 to 1.000 show that the responses of the respondents were close to one another.

\section{Research question two.}

What are the mental and emotional health needs of adolescents in Rivers State according to gender? Data answering this research question are contained in Table 2.

Table:2. Mean Rating of Mental and Emotional Health Needs of Adolescents According to Gender

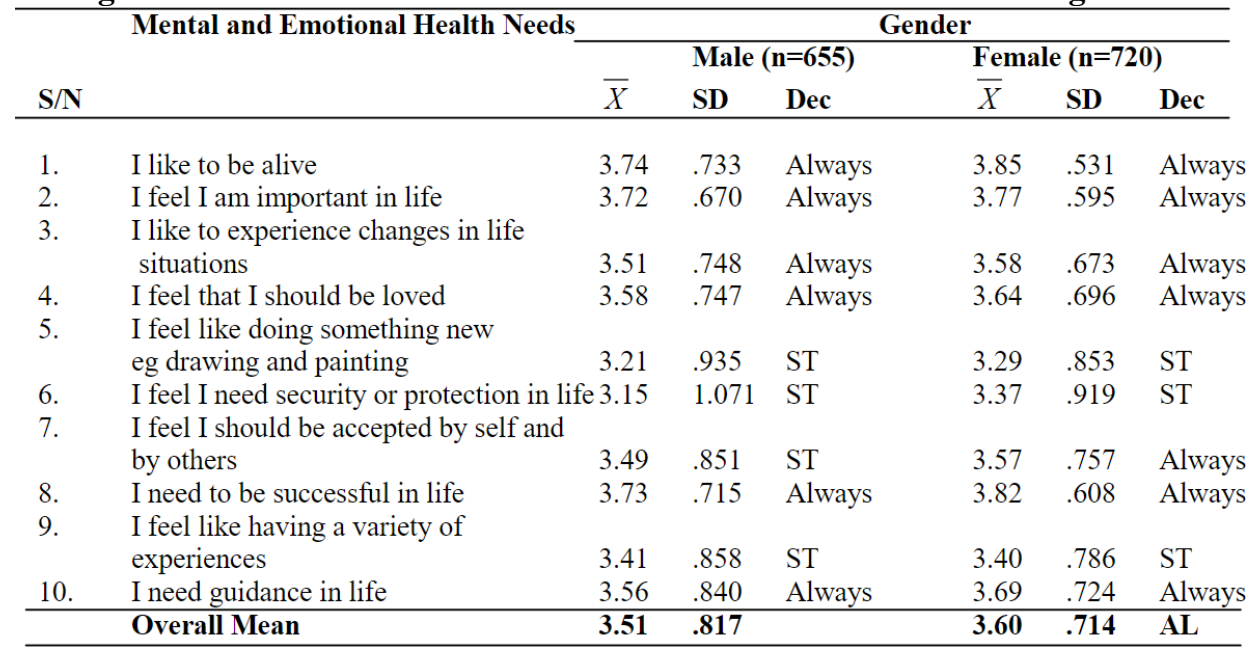

Data in Table 2 show the mean scores and standard deviation according to gender for the items: I like to be alive (male $=$ $\bar{X}=3.74, \mathrm{SD}=.733 ;$ Female $=\bar{X}=3.85, \mathrm{SD}=.531$ ); I need to be successful in life (male $=\bar{X}=3.73, \mathrm{SD}=.715 ; \mathrm{female}=$ $\bar{X}=3.83, \mathrm{SD}=.608$ ); I feel I am important in life (male $=\bar{X}=3.72, \mathrm{SD}=.670$; female $=\bar{X}=3.77, \mathrm{SD}=.595)$; I feel that I should be loved (male $=\bar{X}=3.58, \mathrm{SD}=.747$; female $=\bar{X}=3.64, \mathrm{SD}=.696)$; I need guidance in life $(\mathrm{male}=X=3.56, \mathrm{SD}=$ .840 ; female $=X=3.69, \mathrm{SD}=.724)$ and I like to experience changes in life situations (male $=\bar{X}=3.51, \mathrm{SD}=.748 ;$ female $=\bar{X}=3.58, \mathrm{SD}=.673$ ) which fell between the means of 3.50 to 4.00 . This implies that both male and female adolescents have these needs always. The table further shows that the mean scores and standard deviations for items: I feel like having a variety of experiences (male $=\bar{X}=3.41, \mathrm{SD}=.858$, female $=\bar{X}=3.40, \mathrm{SD}=.786$ ); I feel like doing something new e.g drawing and painting (male $=\bar{X}=3.21, \mathrm{SD}=.935$, female $=\bar{X}=3.29, \mathrm{SD}=.853$ ) and I feel I need security or protection in life (male $=\bar{X}=3.15, \mathrm{SD}=1.071$, female $=\bar{X}=3.37, \mathrm{SD}=.919)$ which fell between the means of 2.50 to 3.49 . This implies that both the male and female adolescents have these needs sometime. Furthermore, the table shows that the mean scores and standard deviation for the item I feel I should be accepted by self and by others (male $=\bar{X}=3.49, \mathrm{SD}=.851$, female $=\bar{X}=3.57, \mathrm{SD}=.757)$. This implies that the male adolescents have this need sometime while the female adolescents have this need always. The table also indicated an overall mean rating of 3.51 for the male and 3.60 for the female. These imply that both the male and female adolescents have mental and emotional health needs always. The standard deviations which range from .531 to 1.071 shows that the responses of the respondents were close one another.

\section{Research question 3.}

What are the mental and emotional health needs of adolescents in Rivers State according to age? Data answering this research question are contained in Table 3. 
Table:3. Mean Rating of Mental and Emotional Health Needs of Adolescents According to Age

\begin{tabular}{|c|c|c|c|c|c|c|c|c|c|c|}
\hline \multirow{3}{*}{\multicolumn{2}{|c|}{$\begin{array}{l}\text { Mental and Emotional Health Needs } \\
\text { S/N }\end{array}$}} & \multicolumn{9}{|c|}{ Age } \\
\hline & & \multicolumn{3}{|c|}{$10-15 y r s(n=494)$} & \multicolumn{3}{|c|}{$16-18 y r s(n=499)$} & \multicolumn{3}{|c|}{$19-24 y r s(n=382)$} \\
\hline & & \multirow{2}{*}{$\frac{\bar{X}}{3.82}$} & \multirow{2}{*}{$\begin{array}{c}\text { SD } \\
.597\end{array}$} & \multirow{2}{*}{$\begin{array}{l}\text { Dec } \\
\mathrm{AL}\end{array}$} & \multirow{2}{*}{$\frac{\bar{X}}{3.78}$} & \multirow{2}{*}{$\begin{array}{l}\text { SD } \\
.645\end{array}$} & \multirow{2}{*}{ Dec } & \multirow{2}{*}{$\frac{\bar{X}}{3.79}$} & \multirow{2}{*}{$\begin{array}{l}\text { SD } \\
.678\end{array}$} & \multirow{2}{*}{ Dec } \\
\hline 1 . & I like to be alive & & & & & & & & & \\
\hline 2. & I feel I am important in life & 3.76 & .639 & $\mathrm{AL}$ & 3.72 & .671 & $\mathrm{AL}$ & 3.76 & .568 & $\mathrm{AL}$ \\
\hline 3. & I like to experience changes in & & & & & & & & & \\
\hline & life situations & 3.60 & .687 & $\mathrm{AL}$ & 3.53 & .715 & $\mathrm{AL}$ & 3.51 & .731 & $\mathrm{AL}$ \\
\hline 4. & I feel that I should be loved & 3.61 & .750 & $\mathrm{AL}$ & 3.62 & .668 & $\mathrm{AL}$ & 3.60 & .752 & $\mathrm{AL}$ \\
\hline 5. & I feel like doing something new & & & & & & & & & \\
\hline & eg drawing and painting & 3.34 & .871 & ST & 3.27 & .859 & ST & 3.11 & .950 & ST \\
\hline 6. & $\begin{array}{l}\text { I feel I need security or protection } \\
\text { in life }\end{array}$ & 3.27 & 1.015 & ST & 3.26 & .979 & ST & 3.27 & 1.009 & ST \\
\hline 7. & $\begin{array}{l}\text { I feel I should be accepted by self } \\
\text { and by others }\end{array}$ & 3.50 & .830 & $\mathrm{AL}$ & 3.48 & .834 & ST & 3.65 & & \\
\hline 8. & I need to be successful in life & 3.80 & .627 & $\mathrm{AL}$ & 3.71 & .742 & $\mathrm{AL}$ & 3.82 & .587 & $\mathrm{AL}$ \\
\hline 9. & $\begin{array}{l}\text { I feel like having a variety of } \\
\text { experiences }\end{array}$ & 3.49 & .772 & ST & 3.29 & .863 & ST & 3.43 & .812 & ST \\
\hline 10. & I need guidance in life & 3.62 & .822 & $\mathrm{AL}$ & 3.63 & .799 & $\mathrm{AL}$ & 3.65 & .711 & $\mathrm{AL}$ \\
\hline & Overall Mean & 3.58 & .761 & $\mathbf{A L}$ & 3.53 & .778 & $\mathbf{A L}$ & 3.56 & .751 & $\mathbf{A L}$ \\
\hline
\end{tabular}

Data in Table 3 show the mean scores and standard deviations for mental and emotional health needs of adolescents as follows: I like to be alive $(10-15 \mathrm{yrs}=\bar{X}=3.82, \mathrm{SD}=.597 ; 1618 \mathrm{yrs}=\bar{X}=3.78, \mathrm{SD}=.645 ; 19-24 \mathrm{yrs}=\bar{X}=3.79, \mathrm{SD}=.678), \mathrm{I}$ need to be successful in life $(1015 \mathrm{yrs}=\bar{X}=3.80, \mathrm{SD}=.627 ; 16-18 \mathrm{yrs}=\bar{X}=3.71, \mathrm{SD}=.742 ; 19-24 \mathrm{yrs}=\bar{X}=3.82, \mathrm{SD}=.587)$; I feel I am important in life $(10-15 \underline{\mathrm{yrs}}=\bar{X}=3.76, \mathrm{SD}=.639 ; 16-18 \mathrm{yrs}=\bar{X}=3.72, \mathrm{SD}=.671 ; 19-24 \mathrm{yrs}=3.76, \mathrm{SD}=.568)$; I need guidance in life $(10-15 \mathrm{yrs}=\bar{X}=3.62, \mathrm{SD}=.822 ; 16-18 \mathrm{yrs}=\bar{X}=3.63, \mathrm{SD}=.799 ; 18-24 \mathrm{yrs}=\bar{X}=3.65, \mathrm{SD}=.711) ; \mathrm{I}$ feel that I should be loved $(10-15 \mathrm{yrs}=3.61, \mathrm{SD}=.750 ; 16-18 \mathrm{yrs}=\bar{X}=\mathrm{SD}=.668 ; 19-24 \mathrm{yrs}=\bar{X}=3.60, \mathrm{SD}=.752)$; and $\mathrm{I}$ like to experience changes in life situations $(10=15 \mathrm{yrs}=\bar{X}=3.60, \mathrm{SD}=.687 ; 16-18 \mathrm{yrs}=\bar{X}=3.53, \mathrm{SD}=7.15 ; 19-24 \mathrm{yrs}=$ $\bar{X}=3.51, \mathrm{SD}=.731)$ which fell between the means of 3.50 and 4.00 . This implies that all the age groups have these needs always.

The table further shows that for I feel I should be accepted by self and by others $(10-15 \mathrm{yrs}=\bar{X}=3.50, \mathrm{SD}=.830 ; 16$ $18 \mathrm{yrs}=\bar{X}=3.48, \mathrm{SD}=.834 ; 19-24 \mathrm{yrs}=\bar{X}=3.65, \mathrm{SD}=.715)$ which fell between the means of 3.50 and 4.00 for age $10-$ $15 y r s$ and 19-24yrs; and 2.50-3.49 for age 16-18yrs. This implies that age group 10-15yrs and 19-24yrs have this need always while age 16-18yrs have the need sometime. Furthermore, for other items, the data are as follows: I feel like having a variety of experiences $(10-15 \mathrm{yrs}=\bar{X}=3.49, \mathrm{SD}=.772 ; 16-18 \mathrm{yrs}=\bar{X}=3.29, \mathrm{SD}=.863 ; 19-24 \mathrm{yrs}=\bar{X}=3.43)$; I feel like doing something new $(10-15 \mathrm{yrs}=\bar{X}=3.34, \mathrm{SD}=.871 ; 16-18 \mathrm{yrs}=3.27, \mathrm{SD}=.859 ; 19-24 \mathrm{yrs}=\bar{X}=3.11, \mathrm{SD}=.950)$; and $\mathrm{I}$ feel I need security or protection in life $(10-15 \mathrm{yrs}=\bar{X}=3.27, \mathrm{SD}=1.015 ; 16-18 \mathrm{yrs}=\bar{X}=3.26, \mathrm{SD}=.979 ; 19-24 \mathrm{yrs}=3.27$, $\mathrm{SD}=1.009)$ which fell between the means of 2.50 and 3.49. This implies that the three age groups sometime have these needs. The overall means for the three age groups $(10-15 \mathrm{yrs}=\bar{X}=3.58, \mathrm{SD}=.761 ; 16-18 \mathrm{yrs}=\bar{X}=3.53, \mathrm{SD}=.778$; $19=24 \mathrm{yrs}=\bar{X}=3.56, \mathrm{SD}=.751)$ fell between the means of 3.50 and 4.00 . This implies that all the age groups always have all the needs. The overall standard deviations which range from .751 to .778 show that the responses of the respondents were close to one another.

\section{Research question 4.}

What are the mental and emotional health needs of adolescents in Rivers State by location? Data answering this research question are contained in Table 4.

Table:4. Mean Rating of Mental and Emotional Health Needs of Adolescents by Location

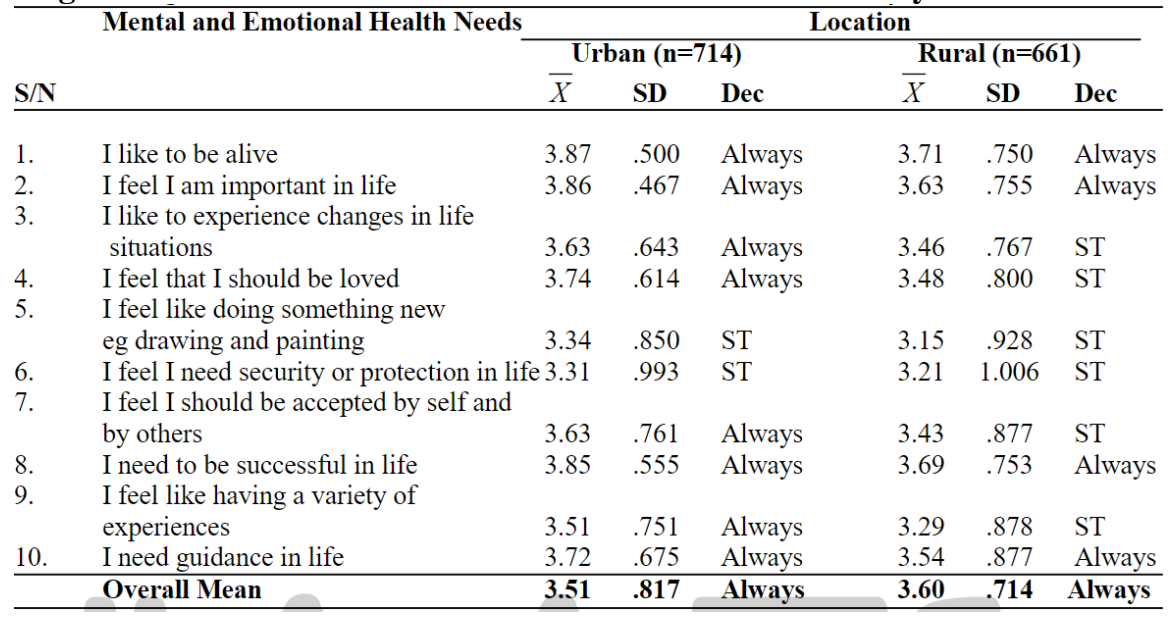


Data in Table 4 show the mean scores and standard deviations by location for these health needs: $\mathrm{I}$ like to be alive (urban= $\bar{X}=3.87, \mathrm{SD}=.500$, rural $=\bar{X}=3.71, \mathrm{SD}=.750$ ); I feel I an important in life (urban $=\bar{X}=3.86, \mathrm{SD}=.467 ;$ rural $=\bar{X}=$ $3.63, \mathrm{SD}=.755$ ); I need to be successful in life (urban $=\bar{X}=3.85, \mathrm{SD}=.555$; rural $=\bar{X}=3.69, \mathrm{SD}=.753$ ); and $\mathrm{I}$ need guidance in life (urban $=\bar{X}=3.72, \mathrm{SD}=.675$; rural $=\bar{X}=3.54, \mathrm{SD}=.877$ ) which fell between the means of 3.50 and 4.00 . This implies that both the urban and rural adolescents have these needs always.

The table further shows that I feel that I should be loved (urban $=\bar{X}=3.74, \mathrm{SD}=.614$; rural $=\bar{X}=3.48$ ); I like to experience changes in life situations (urban $=\bar{X}=3.63, \mathrm{SD}=.643$; rural $=\bar{X}=3.46$ ); I feel I should be accepted by self and by others (urban $=\bar{X}=3.63, \mathrm{SD}=.761 ;$ rural $=\bar{X}=3.43, \mathrm{SD}=.877$ ) and $\mathrm{I}$ feel like having a variety of experiences (urban $=\bar{X}=3.51$, $\mathrm{SD}=.751$; rural $=\bar{X}=3.29, \mathrm{SD}=.878$ ) fell between the means of 3.50 and 4.00 for urban location; and 2.50 and 3.49 for rural location. This implies that the adolescents in urban location have these needs always while the adolescents in rural location sometime have these needs. Furthermore, the data for the needs I feel like doing something new (urban $=\bar{X}=$ $3.34, \mathrm{SD}=.850$; rural $=\bar{X}=3.25, \mathrm{SD}=.928$ ); and I feel I need security and protection in life (urban $=\bar{X}=3.31, \mathrm{SD}=.993$; rural $=\bar{X}=3.21, \mathrm{SD}=1.006$ ) fell between the means 2.50 and 3.49 . This implies that both the adolescents in urban and rural locations sometime have these needs. The overall means and standard deviations (urban $=\bar{X}=3.51, \mathrm{SD}=.817$; rural $=$ $\bar{X}=3.60, \mathrm{SD}=.714)$ fell between the means of 3.50 and 4.00 . This implies that both the urban and rural adolescents always have these needs. The standard deviation which range from .714 to .817 show that the responses of the respondents were close to one another.

\section{Hypothesis one.}

There is no significant gender difference in the mental and emotional health needs of adolescents. Data testing this hypothesis are contained in Table 5.

Table:5. Result of the t-Test Testing the Hypothesis of No Significant Difference in the Mental and Emotional Health Needs of Adolescents According to Gender.

\begin{tabular}{llllllll}
$\begin{array}{l}\text { Mental and Emotional } \\
\text { Health Needs }\end{array}$ & Gender & $\mathbf{n}$ & $\bar{X}$ & df & SD & t-cal & P-value \\
\hline Mental and Emotional & Male & 655 & 35.64 & 1373 & 4.560 & .633 & .527 \\
Health Needs & Female & 720 & 35.48 & & 4.841 & & \\
\hline
\end{tabular}

Table 5 shows the $t$-value and the corresponding P-value at 1373 degree of freedom for mental and emotional health needs $(\mathrm{t}=.633, \mathrm{P}=.527)$ which are greater than .05 level of significance. The null hypothesis of no significant difference is accepted. This implies that the mental and emotional health needs of the male and female adolescents do not differ according to gender.

\section{Hypothesis two.}

There is no significant age difference in the mental and emotional health needs of adolescents. Data testing this hypothesis are contained in Table 6.

Table:6. Result of One-Way ANOVA Testing the Hypothesis of No Significant Difference in the Mental and Emotional Health Needs of Adolescents According to Age.

\begin{tabular}{lllllll}
\hline $\begin{array}{l}\text { Mental and } \\
\begin{array}{l}\text { Emotional } \\
\text { Health Needs }\end{array}\end{array}$ & $\begin{array}{c}\text { Sum of } \\
\text { squares }\end{array}$ & df & $\begin{array}{c}\text { Mean } \\
\text { square }\end{array}$ & F-cal & P-value \\
\hline Mental and Emotional & Between Groups & 15.272 & 2 & 7.636 & .344 & .709 \\
Health Needs & Within Groups & 30439.528 & 1372 & 22.186 & & \\
\hline
\end{tabular}

Table 6 shows the F-value and the corresponding P-value at 2 and 1372 degrees of freedom for mental and emotional health needs $(\mathrm{F}=.344, \mathrm{P}=.709)$ is greater than .05 level of significance. The null hypothesis of no significant difference is accepted. This implies that mental and emotional health needs of the adolescents did not differ according to age.

\section{Hypothesis three.}

There is no significant difference in the mental and emotional health needs of adolescents owning to location. Data testing this hypothesis are contained in Table 7. 
Table:7. Result of the t-Test Testing the Hypothesis of No Significant Difference in the Mental and Emotional Health Needs of Adolescents According to Location.

\begin{tabular}{llllllll}
\hline $\begin{array}{l}\text { Mental and Emotional } \\
\text { Health Needs }\end{array}$ & Location & $\mathbf{n}$ & $\bar{X}$ & df & SD & t-cal & P-value \\
\hline Mental and Emotional & Urban & 714 & 35.56 & 1373 & 4.729 & .036 & .971 \\
Health Needs & Rural & 661 & 35.56 & & 4.688 & & \\
\hline
\end{tabular}

Table 7 shows the t-value and corresponding P-value at 1373 degree of freedom for mental and emotional health needs ( $\mathrm{t}$ $=.036, \mathrm{P}=.971)$ which are greater than .05 level of significance. The null hypothesis of no significant difference by location was accepted. This implies that the mental and emotional health needs of the urban and rural adolescents did not differ.

\section{Discussion}

The findings in Table 1 revealed that the adolescents have mental and emotional health needs in life. They have the following needs always: I like to be alive, I feel I am important in life, I like to experience changes in life situations, I feel that I should be loved, I feel I should be accepted by self and by others, I need to be successful in life and I need guidance in life. The Table further revealed that the adolescents indicated having these needs sometime: I feel like doing something new, I need security or protection in life, I feel like having a variety of experiences. This finding is expected and not surprising because it is in line with the finding of Kidiger et al (2009) whose study revealed that a majority of the students discussed the importance of having someone to talk to when coping with emotional difficulty and accessing help sources. Little wonder did Reed-Flora and Lang (1982) mentioned that these needs are essential to mental health. This finding through focus group discussion revealed that all the respondents have these needs always. More so, experience has shown that the adolescents needs love and to accepted that is why some of them indulge in opposite sex sexual relationship.

The findings in Table 2 revealed that both the male and female adolescents have the following needs always: I like to be alive; I feel I am important in life; I like to experience changes in life situations; I feel I should be loved; I need to be successful in life and I need guidance in life. The table findings further revealed that both the male and female adolescents have the following needs sometime: I feel like doing something new; I feel I need security in life; and I feel like having a variety of experiences. More so, the female adolescents indicated I feel that I should be accepted by self and by others always while the male adolescents indicated that they have this need sometime. The overall means showed that both the male and female adolescents have mental and emotional health needs always. This finding is expected and not surprising because everybody needs to be loved, to live, to be accepted, security and success in life irrespective of gender. The finding through focus group discussion showed that all the groups pointed out that both the male and female adolescents have mental and emotional health needs such as need to be loved, need to for guidance in life, need to be successful in life and to be empowered (trained on skills).

The findings in Table 3 revealed that the three age groups (10-15yrs; 16-18yrs and 1924yrs) have the following needs always: I like to be alive; I feel I am important in life; I like to experience changes in life situations; I feel I should be loved; I need to be successful in life; and I need guidance in life. Furthermore, all the age groups that they need the following needs sometime: I feel like doing something new; I feel I need security or protection in life; and I feel like having a variety of experiences. For the need that I feel I should be accepted by self and by others, age groups 10-15yrs and 19-24yrs indicated that they have the needs always while age group 16-18yrs indicated that they have the needs sometime. The overall means of each of the three age groups showed that all the age groups have mental and emotional needs always. This finding is expected and not surprising because according to Reed-Flora and Lang (1982), essential to mental health and life itself, is our emotional health needs. Experience has also shown that nobody wants to die; everybody needs to be accepted by others and be loved. Furthermore, as a result of the quest for love, most adolescents indulge in opposite sex relationship and illicit sexual activities which may result to unwanted pregnancy and leave them with emotional trauma. The finding through focus group discussion showed that all the groups pointed out that all the age groups adolescents have mental and emotional health needs

The findings in Table 4 revealed that both the urban and rural adolescents have the following needs always: I like to be alive; I feel I am important in life; I need to be successful in life and I need guidance in life. Furthermore, the urban adolescents indicated that they have the following needs always while the rural adolescents indicated they have the needs sometime: I like to experience changes in life situations; I feel I should be loved; I feel I should be accepted by self and by others; and I feel like having a variety of experiences. For the following needs, both the urban and rural adolescents indicated that they have them sometime: I feel like doing something new; and I feel I need security or protection in life. The overall means for both the urban and rural adolescents showed that they have the needs always. This finding is expected and not surprising because both the urban and rural adolescents have needs such as mental and emotional health needs. The finding through focus group discussion revealed that all the groups pointed out that both the urban and rural adolescent have mental and emotional health needs

The finding in Table 5 revealed that there is no significant difference in the mental and emotional health needs of adolescents according to gender. This finding is expected and not surprising because literature has shown that everybody irrespective of gender or sex have mental and emotional health needs such as the need to be loved, need to live, need for protection or security, need to succeed in life, guidance and acceptance. The finding agrees with the observation of Reed- 
Flora and Lang (1982) who observed that our emotional needs include need to live, need to feel important, need for variety, need to be loved, need to achieve, and need for value orientation. The finding through focus group discussion revealed that all the groups pointed out that the both the male and female adolescents have these needs and in addition, the need for adolescents empowerment.

The findings in Table 6 revealed that there is no significant difference in the mental and emotional health needs of adolescents according to age. This finding is expected and not surprising because literature has shown that everybody irrespective of age and even children from birth have mental and emotional health needs such as need curdled by their mother and people around them (love), need for protection or security, guidance and acceptance. The finding agrees with the observation of Reed-Flora and Lang (1982) who observed that our emotional needs include need to live, need to feel important, need for variety, need to be loved, need to achieve, and need for value orientation. The finding through focus group discussion revealed that all the groups pointed out that the adolescents in all the age groups have these needs and in addition, the need for adolescents' empowerment.

The finding in Table 7 revealed that there is no significant difference in the mental and emotional health needs of adolescents according to location. This finding is expected and not surprising because experience has shown that everybody irrespective of location has mental and emotional health needs such as the need to be loved, that is why people including urban and rural adolescents indulge in opposite sex relationship. The need to live that is why people including urban and rural adolescents go to hospital for treatment when they are sick and seek for empowerment to sustain life. The need for protection or security and need to succeed in life that is why both the urban and rural adolescents seek to go to school or are engaged with hawking or trading and other forms of labour. They also have the needs to experience changes in life and create something new, that is why they are adventurous and always trying to discover things for themselves. The finding through focus group discussion revealed that all the groups pointed out that both the rural and urban adolescents have all the needs such as the need for guidance and acceptance.

\section{Summary of Major Findings}

1. An overall mean rating of 3.55 for mental and emotional health needs shows that the adolescents have the needs always. This is contained in Table 1 .

2. Both male $(\bar{X}=3.51)$ and female $(\bar{X}=3.60)$ adolescents have mental and emotional health needs always. These are contained in Table 2.

3. The overall means for the three age groups $(10-15 \mathrm{yrs}=\bar{X}=3.58, \mathrm{SD}=.761 ; 16-18 \mathrm{yrs}=\bar{X}=3.53, \mathrm{SD}=.778 ; 19=24 \mathrm{yrs}=$ $\bar{X}=3.56, \mathrm{SD}=.751)$ show that all the age groups always have all the mental and emotional health needs. These are contained in Table 3.

4. The overall means of urban $(\bar{X}=3.51, \mathrm{SD}=.817)$ and rural $(\bar{X}=3.60, \mathrm{SD}=.714)$ adolescents show that both the urban and rural adolescents always have the needs. These are contained in Table 4.

5. Both male $(\bar{X}=3.51)$ and female $(\bar{X}=3.60)$ adolescents have mental and emotional health needs always. These are contained in Table 5 .

6. The overall means for the three age groups $(10-15 \mathrm{yrs}=\bar{X}=3.58, \mathrm{SD}=.761 ; 16-18 \mathrm{yrs}=\bar{X}=3.53, \mathrm{SD}=.778 ; 19=24 \mathrm{yrs}=$ $\bar{X}=3.56, \mathrm{SD}=.751)$ show that all the age groups always have all the mental and emotional health needs. These are contained in Table 6.

7. The overall means of urban $(\bar{X}=3.51, \mathrm{SD}=.817)$ and rural $(\bar{X}=3.60, \mathrm{SD}=.714)$ adolescents show that both the urban and rural adolescents always have mental and emotional health needs. These are contained in Table 7.

\section{Conclusions}

Based on the major findings and the discussion of the findings in this study, it was concluded that:

1. Adolescents in Rivers State have mental and emotional health needs always

2. Both male and female adolescents have mental and emotional health needs always

3. The three age groups -10-15, 16-18 and 19-24 years have mental and emotional health needs always

4. Mental and emotional health problems are prevalent among both the urban and rural adolescents

\section{Recommendations}

Based on the findings and conclusions, it is recommended that:

1. Programmes should be put in place in order to meet and satisfy adolescents mental and emotional health needs.

2. Programmes to meet and satisfy adolescents mental and emotional health needs should be incorporated into the school curriculum.

\section{References}

[1].Anaekwe, M.C. (2007). Basic research methods and statistics in education and social sciences. Onicha: Sofic Publication and Printing Ltd.

[2].Deal Fact Sheet (2011). Emotional health. www.samaritans.org. Retrieved June 22, 2011.

[3].Frankel, J.Y. \& Wallen, N.E. (2003). How to design and evaluate research in education (5 ${ }^{\text {th }}$ ed.). New York: McGraw Hill Group of Companies. 
[4].Kidiger, J., Donovan, J.L., Biddle, L., Campbell, R. \& Gunnell, D. (2009). Suppoorting adolescent emotional health in schools: a mixed methods study and staff views in England. BioMed Central Public Health, 9: 403. http://www.biomedcentral.com/14712458/9/403. Retrieved July 25, 2011.

[5].Huffstetler, E. (2013). Wants vs. needs: how to distinguish between the two. About.com guide. www.frugaliving.com/od/.../qtWants_vs_Needs htm. Retrieved June 28, 2013.

[6].National Population Commission (2006). National population census. Federal Republic of Nigeria: 2006 Population Census.

[7].O’Donnell, M.P. (2002). Employer's financial perspective on health promotion. In M. P. O'Donnell, (Ed). Health promotion in the workplace ( $3^{\text {rd }}$ ed). New York: Delmar.

[8].Okafor, J.O. and Okafor, R.U. (1998). Emotional and mental health. Nsukka: Ralja Publishers.

[9].Onuzulike, N. M. (2007). Contemporary health matters. Owerri: CON Publishers.

[10]. Park, K. (2007). Park's textbook of preventive and social medicine. (19 ${ }^{\text {th }}$ ed.). India: M/s Banarsidas Bhanot.

[11]. Reed-Flora, R. \& Lang, T.A. (1982). Health behaviours. USA: West Publishing Co.

[12]. Udoh, C.O \& Ajala, J.A (2012). Understanding mental and social health. Ibadan: Printmarks Ventures.

[13]. Wagner, K. (2008). Personal interview. Maine Middle School Nurse.

[14]. WHO (1998). The second decade: improving health and development. Adolescent health and development programme. Geneva: The Author

[15]. World Health Organization (2005). Promoting mental health: concepts, emerging evidence, practice: a report of the World Health Organization, Department of mental health and substance abuse in collaboration with the Victorian Health Promotion Foundation and the University of Melbourne. WHO, Geneva.

[16]. Your Health (2011). Your health/emotional health. http/www.seniors.gov.au/internet/seniors/publishinf.nsf/Content/Emotional+health. Retrieved on June 22, 2011. 